\title{
Broadband emission in new lead free all-inorganic 3D CsZnCl2l perovskite
}

DOI:

10.1039/C8NJ04404J

\section{Document Version}

Accepted author manuscript

Link to publication record in Manchester Research Explorer

\section{Citation for published version (APA):}

Aamir, M., Khan, M. D., Sher, M., Malik, M. A., Revaprasadu, N., \& Akhtar, J. (2018). Broadband emission in new lead free all-inorganic 3D CsZnCl2l perovskite. New Journal of Chemistry. https://doi.org/10.1039/C8NJ04404J

\section{Published in:}

New Journal of Chemistry

\section{Citing this paper}

Please note that where the full-text provided on Manchester Research Explorer is the Author Accepted Manuscript or Proof version this may differ from the final Published version. If citing, it is advised that you check and use the publisher's definitive version.

\section{General rights}

Copyright and moral rights for the publications made accessible in the Research Explorer are retained by the authors and/or other copyright owners and it is a condition of accessing publications that users recognise and abide by the legal requirements associated with these rights.

\section{Takedown policy}

If you believe that this document breaches copyright please refer to the University of Manchester's Takedown Procedures [http://man.ac.uk/04Y6Bo] or contact uml.scholarlycommunications@manchester.ac.uk providing relevant details, so we can investigate your claim.

\section{OPEN ACCESS}



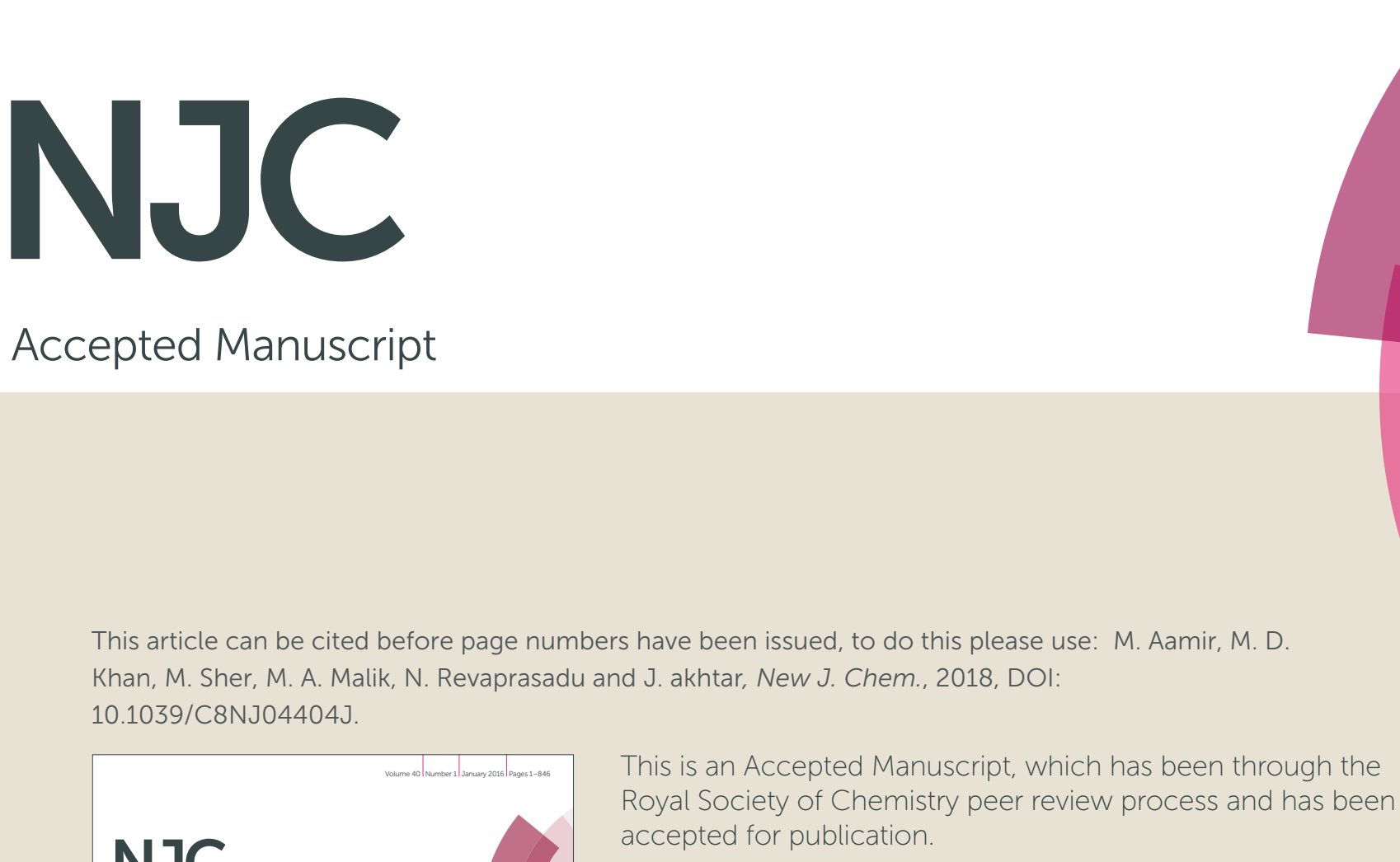

\section{Accepted Manuscript}

This article can be cited before page numbers have been issued, to do this please use: M. Aamir, M. D. Khan, M. Sher, M. A. Malik, N. Revaprasadu and J. akhtar, New J. Chem., 2018, DOI:

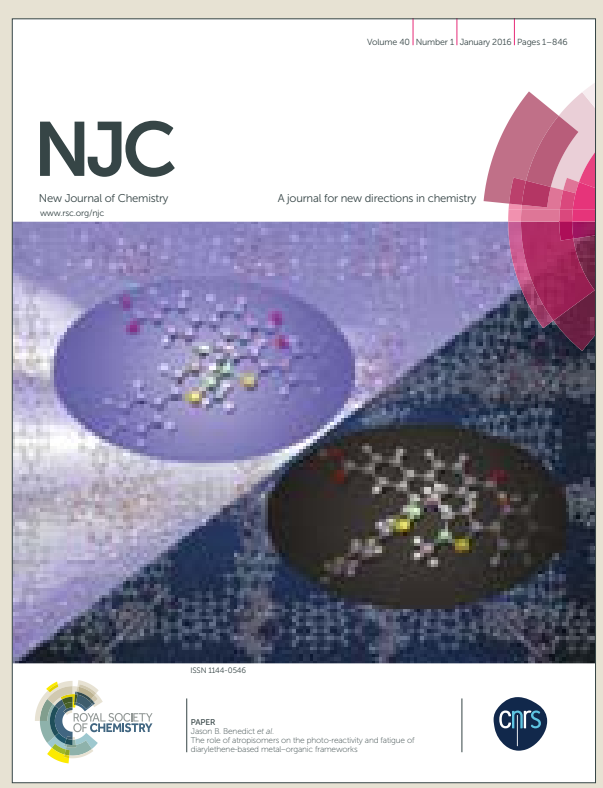

This is an Accepted Manuscript, which has been through the Royal Society of Chemistry peer review process and has been accepted for publication.

Accepted Manuscripts are published online shortly after acceptance, before technical editing, formatting and proof reading. Using this free service, authors can make their results available to the community, in citable form, before we publish the edited article. We will replace this Accepted Manuscript with the edited and formatted Advance Article as soon as it is available.

You can find more information about Accepted Manuscripts in the author guidelines.

Please note that technical editing may introduce minor changes to the text and/or graphics, which may alter content. The journal's standard Terms \& Conditions and the ethical guidelines, outlined in our author and reviewer resource centre, still apply. In no event shall the Royal Society of Chemistry be held responsible for any errors or omissions in this Accepted Manuscript or any consequences arising from the use of any information it contains. 


\section{Journal Name}

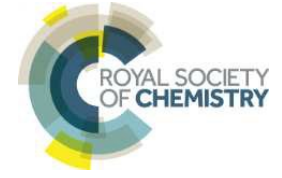

\section{Broadband emission in new lead free all-inorganic 3D $\mathrm{CsZnCl}_{2} \mathrm{I}$ perovskite}

Received 00th January 20xx, Accepted 00th January 20xx

DOI: $10.1039 / x 0 x \times 00000 x$

\author{
Muhammad Aamir, ${ }^{a} *$ Malik Dilshad Khan, ${ }^{b}$ Muhammad Sher, ${ }^{c}$ Neerish Revaprasadu, ${ }^{b}$ \\ Mohammad Azad Malik ${ }^{\text {b, d }}$ Javeed Akhtar, ${ }^{a}$ *
}

www.rsc.org/

This contribution reports the deposition of new zinc based lead free all inorganic 3D $\mathrm{CsZnCl}_{2} 1$ perovskite thin films using aerosol assisted chemical vapour deposition (AACVD) at $100{ }^{\circ} \mathrm{C}$. Room tempertaure optical measurements performed on as-deposited thin films shown two absorption peaks. Upon $325 \mathrm{~nm}$ excitation, $\mathrm{CsZnCl}_{2}$ l perovskite thin film showed broad band white light emission having two peaks, which cover the entire visible range of the spectrum. This is the first example of white light emission from 3D all-inorganic lead free mixed halide $\mathrm{CsZnCl}_{2} \mid$ perovskites.

All inorganic lead halide perovskites have attracted considerable attention due to their remarkable properties including narrow band emission, tunable band gap and high photoluminescence quantum yield. ${ }^{1-3}$ Owing to these merits, they have shown huge potential in the fields of photovoltaics, ${ }^{4}$ fluorescent sensing, ${ }^{5-7}$ photocatalysis, ${ }^{8}$ solid state displays and lighting. ${ }^{9,10}$ Conventionally, the white light emitting devices of perovskite materials suffer from a drawback of nonstoichiometric compositions due to anion exchange during fabrication process. ${ }^{11,12}$ Furthermore, red light emitting, $\mathrm{CsPbl}_{3}$ and $\mathrm{CsPb}(\mathrm{Br} / \mathrm{I})_{3}$ were found to be unstable at ambient conditions due to the phase transition and phase separation phenomenon. $^{13}$

Amongst the lead halide perovskites, white light emitting 2D hybrid perovskite materials have gained enormous attention due to their potential applications in optoelectronics. ${ }^{14}$ These hybrid 2D lead based materials have high color stability and tunability compared to 3D lead halide perovskites. ${ }^{15}$ On the other hand, recently, 3D all inorganic $\mathrm{CsPbCl}_{3}$ perovskite has

\footnotetext{
${ }^{a}$. Department of Chemistry, Materials Laboratory, Mirpur University of Science \& Technology (MUST), Mirpur-10250 (AJK), Pakistan.Email: javeedkt@gmail.com, aamirorg@gmail.com

b. Department of Chemistry, University of Zululand, Private Bag X1001, Kwadlangezwa, 3886, South Africa

Department of Chemistry, Allama Iqbal Open University, Sector H-8, Islamabad44000, Pakistan

d. School of Materials, The University of Manchester, Oxford Road, Manchester M13 9PL, UK.

† Footnotes relating to the title and/or authors should appear here.

Electronic Supplementary Information (ESI) available: [details of any supplementary information available should be included here]. See DOI: $10.1039 / x 0 x x 00000 x$
}

been co-doped with $\mathrm{Bi}^{3+}$ and $\mathrm{Mn}^{2+}$ to obtained white light emission. ${ }^{16} \mathrm{~A}$ major concern with lead based perovskite materials is toxicity, which impedes their commercial applications. As an alternative, divalent $\mathrm{Sn}$ and Ge have been used in perovskite materials, but, chemical instability related to these metal cations faded the charm. ${ }^{17}$

Transition metals such as $\mathrm{Cu}, \mathrm{Zn}$ etc. have stable oxidation state and their high absorption coefficient making them suitable candidates for metal halide perovskite materials., 6 Furthermore, the mixed halides in perovskite have distorted inorganic network that could be interesting to attain broadband white light emission. ${ }^{18}$

Herein, we report the deposition of new all inorganic lead free mixed halide $\mathrm{CsZnCl}_{2} 1$ perovskite thin films via AACVD at $100{ }^{\circ} \mathrm{C}$ from CsI and $\mathrm{ZnCl}_{2}$. The as-deposited 3D lead free $\mathrm{CsZnCl}_{2} \mathrm{I}$ perovskite thin films were characterized by powdered X-ray diffraction spectroscopy ( $p-X R D)$, field emission scanning electron microscopy (FESEM), energy-dispersive X-ray spectroscopy (EDX), UV-Visible (UV-Vis), and photoluminescence spectrophotometry (PL). Two distinct absorption bands and broadband emission due to the selftrapped excited states in the mixed halide inorganic perovskite was observed.

The crystallinity of as-deposited thin film was determined by $p$ XRD. The diffraction peaks at $2 \theta=22.63^{\circ}, 27.02^{\circ}$, $28.41^{\circ}, 31.52^{\circ}, 36.24^{\circ}, 38.66^{\circ}, 43.17^{\circ}, 51.93^{\circ}$, and $60.82^{\circ}$ confirm the formation of the desired $\mathrm{CsZnCl}_{2} 1$ perovskite as shown in figure 1. The $\mathrm{p}-\mathrm{XRD}$ analysis of $\mathrm{Csl}$ and $\mathrm{ZnCl}_{2}$ (starting materials) was also measured. It can be observed that no diffraction peak of $\mathrm{CsZnCl}_{2} \mathrm{I}$ matches with $\mathrm{Csl}$ or $\mathrm{ZnCl}_{2}$, which confirms the formation of the deposited $\mathrm{CsZnCl}_{2} \mid$ perovskite material.

Morphology of as-deposited thin films was explored by using field emission scanning electron microscopy (FESEM). The mixed morphologies including tetragonal and some irregularly shaped clusters of plates like structures were formed by $\mathrm{CsZnCl}_{2}$ l perovskite as shown in figure $2(\mathrm{a}-\mathrm{b})$. The substrate was uniformly covered with the deposited material. To confirm the presence of $\mathrm{Cs}, \mathrm{Zn}, \mathrm{Cl}$, and I in the as-deposited thin films, 
EDX elemental mapping was performed. The uniform distribution of $\mathrm{Cs}, \mathrm{Zn}, \mathrm{Cl}$ and I in the as-deposited film validates the formation of $\mathrm{CsZnCl}_{2}$ l perovskite as shown in figure 2 (c-f).

The optical properties of the as-deposited films were determined by UV-Vis and photoluminescence spectroscopy. Room temperature absorption spectra of thin films of allinorganic mixed halide $\mathrm{CsZnCl}_{2} \mathrm{l}$ perovskite show two absorption peaks located at $2.67 \mathrm{eV}(4.65 \mathrm{~nm})$ and $3.45 \mathrm{eV}$ $(360 \mathrm{~nm})$ as presented in Figure $3(\mathrm{a})$. These absorption peaks assigned to the exciton confined into the $\left[\mathrm{ZnCl}_{2} \mathrm{l}\right]^{-1}$ inorganic part and attributed to the electronic transition from the top of valance band including $\mathrm{Cl}(3 p)$ and I (5p) orbitals to the bottom of the conduction band of the $\mathrm{Zn}(4 \mathrm{~s})$ orbital. The appearance of two peaks may be due to the energy level difference between $\mathrm{Cl}(3 p)$ and $\mathrm{I}(5 \mathrm{p})$ orbitals. ${ }^{19}$ Furthermore, the presence of excitonic absorption peak (3.45 eV) at room temperature indicates a larger exciton binding energy. ${ }^{19} \mathrm{PL}$ spectrum of the as-deposited thin films of $\mathrm{CsZnCl}_{2} 1$ was measured at room temperature at $325 \mathrm{~nm}$ (3.815 eV) excitation frequency. As shown in Figure $3 b$, very broadband white light (WL) emission which covers almost whole visible spectrum ( $370 \mathrm{~nm}$ to 630 $\mathrm{nm}$ ) consisting of two bands positioned at $2.28 \mathrm{eV}$ and $2.87 \mathrm{eV}$, respectively. We assigned high energy broad PL (2.87 eV) peak related to the exciton absorption located at $3.45 \mathrm{eV}$. This broad PL emission show large stoke shift of $390 \mathrm{meV}$. On the other hand, the peak ( $2.67 \mathrm{eV}$ ) belongs to the broader exciton absorption peak located at $2.67 \mathrm{eV}$ with stoke shift of 450 meV.

These two peaks together form a very broadband emission with maximum intensity at $2.87 \mathrm{eV}$, and a full width half maximum (FWHM) of $1.12 \mathrm{eV}$ (Figure 3b). This type of broadband WL emission was reported for low dimensional hybrid perovskite materials. ${ }^{20-22}$ Recently, two dimensional $\left(\mathrm{C}_{6} \mathrm{H}_{11} \mathrm{NH}_{3}\right)_{2} \mathrm{CdBr}_{4}$ hybrid perovskite show similar broadband emission. ${ }^{23}$ Dohner et al. ${ }^{14}$ have reported three single crystals of $\left[2,2^{\prime}\right.$-(ethylenedioxy)bis (ethylammonium) $]\left[\mathrm{PbX}_{4}\right](\mathrm{X}=\mathrm{Cl}, \mathrm{Br}, \mathrm{I})$ which also show comparable broad band emission with FWHM of $0.95 \mathrm{eV}, 0.80 \mathrm{eV}$ and $0.32 \mathrm{eV}$. However, present work represents first 3D all-inorganic lead free mixed halide $\mathrm{CsZnCl}_{2} \mathrm{I}$ perovskite with broadband emission. The origin of this broadband emission may be due to the distortion originated from the mixed halide ions with orbitals of different energies in the all-inorganic $\mathrm{CsZnCl}_{2}$ l perovskite structure. The lead-free nature and broadband emission make this material an exciting candidate for optoelectronic applications.

In summary, we reported the deposition of new lead free all inorganic 3D mix halide $\mathrm{CsZnCl}_{2} \mathrm{l}$ perovskite thin films using AACVD at $100{ }^{\circ} \mathrm{C}$ for 30 minutes. The as-deposited thin films were characterized by $\mathrm{p}$-XRD, SEM and EDX. The $\mathrm{CsZnCl}_{2} \mathrm{I}$ thin films have shown two absorption peaks and broadband $\mathrm{PL}$ emission with FWHM of $1.12 \mathrm{eV}$, which is larger or equal to reported emission shown by $2 \mathrm{D}$ hybrid perovskites. ${ }^{23}$ As far as we know this is the first example of all-inorganic lead free mixed halide perovskite showing broad white light emission. This study can open up a new venue for 3D all inorganic perovskites to be explored as white light emitters. The optoelectronic device application is under progress and will be produced shortly.

\section{Experimental section}

\section{Deposition of thin films by AACVD}

$\mathrm{CsZnCl}_{2} \mathrm{l}$ thin films were deposited on glass substrates consuming stoichiometric ratio of precursors zinc chloride and cesium iodide via AACVD at $100{ }^{\circ} \mathrm{C}$ using our previously reported method. ${ }^{24,25}$

\section{Materials \& Characterization}

Cesium iodide (CsI), Zinc chloride $\left(\mathrm{ZnCl}_{2}\right)$, and anhydrous DMF were purchased from Sigma-Aldrich and used without further purification. $\mathrm{p}$-XRD measurements were performed using a Bruker aXS D8 advanced diffractometer with $\mathrm{Cu}-\mathrm{K} \alpha$ radiation $(\lambda=1.5406 \AA$ ) operated at $40 \mathrm{kV}$ and $40 \mathrm{~mA}$. Field emission scanning electron microscopy (SEM) was carried out using a Philips XL30 FEG SEM. Energy-dispersive analysis of $X$-rays (EDX) spectroscopy was performed using a DX4 detector. All samples were carbon coated using Edwards coating system E306A prior to SEM analysis. A Perkin-Elmer Lamda 20 UV-vis spectrophotometer was used to carry out optical measurements in the $200-1100 \mathrm{~nm}$ wavelength range at room temperature. Samples were placed in quartz cuvettes $(1 \mathrm{~cm}$ path length) and the absorbance was recorded. Photoluminescence $(\mathrm{PL})$ spectra were recorded on a PerkinElmer LS 55 luminescence spectrometer with xenon lamp over range of $200-800 \mathrm{~nm}$.

\section{Acknowledgements}

JA thanks to ORIC, Mirpur University of Science and Technology (MUST) for funding (ORIC/381/2018).

\section{Conflicts of interest}

There are no conflicts to declare.

\section{References}

1. G. Li, F. W. R. Rivarola, N. J. Davis, S. Bai, T. C. Jellicoe, F. de la Peña, S. Hou, C. Ducati, F. Gao and R. H. Friend, Adv. Mater., 2016, 28, 3528-3534.

2. C. Yin, L. Chen, N. Song, Y. Lv, F. Hu, C. Sun, W. Y. William, C. Zhang, X. Wang and Y. Zhang, Phys. Rev. Lett., 2017, 119, 026401.

3. M. Aamir, T. Adhikari, M. Sher, M. D. Khan, J. Akhtar and J. M. Nunzi, Chem. Rec., 2018, 18, 230-238.

4. M. Aamir, T. Adhikari, M. Sher, N. Revaprasadu, W. Khalid, J. Akhtar and J.-M. Nunzi, New J. Chemistry, 2018, 42, 14104-14110.

5. M. Aamir, M. Sher, M. A. Malik, J. Akhtar and N Revaprasadu, New J. Chemistry, 2016, 40, 9719-9724.

6. M. Aamir, M. Sher, M. A. Malik, N. Revaprasadu and J. Akhtar, Mater. Lett., 2016, 183, 135-138. 


\section{Journal Name}

7. M. Aamir, M. D. Khan, M. Sher, S. V. Bhosale, M. A. Malik, J. Akhtar and N. Revaprasadu, Eur. J. Inorg. Chem., 2017, 2017, 3755-3760.

8. M. Aamir, Z. H. Shah, M. Sher, A. Iqbal, N. Revaprasadu, M. A. Malik and J. Akhtar, Mater. Sci. Semicond. Process., 2017, 63, 6-11.

9. F. Hu, C. Yin, H. Zhang, C. Sun, W. W. Yu, C. Zhang, X. Wang, Y. Zhang and M. Xiao, Nano Lett., 2016, 16, 64256430.

10. C. Sun, Y. Zhang, C. Ruan, C. Yin, X. Wang, Y. Wang and W. W. Yu, Adv. Mater., 2016, 28, 10088-10094.

11. X. Zhang, C. Sun, Y. Zhang, H. Wu, C. Ji, Y. Chuai, P. Wang, S. Wen, C. Zhang and W. W. Yu, J. Phys. Chem. Lett., 2016, 7, 4602-4610.

12. C. C. Stoumpos, C. D. Malliakas and M. G. Kanatzidis, Inorg. Chem., 2013, 52, 9019-9038.

13. C. Wang, A. S. Chesman and J. J. Jasieniak, Chem. Commun., 2017, 53, 232-235.

14. E. R. Dohner, A. Jaffe, L. R. Bradshaw and H. I. Karunadasa, J. Am. Chem. Soc., 2014, 136, 13154-13157.

15. L. Mao, Y. Wu, C. C. Stoumpos, M. R. Wasielewski and M. G. Kanatzidis, J. Am. Chem. Soc., 2017, 139, 5210-5215.

16. H. Shao, X. Bai, H. Cui, G. Pan, P. Jing, S. Qu, J. Zhu, Y. Zhai, B. Dong and H. Song, Nanoscale, 2018, 10, 1023-1029.

17. N. K. Noel, S. D. Stranks, A. Abate, C. Wehrenfennig, S. Guarnera, A.-A. Haghighirad, A. Sadhanala, G. E. Eperon, S. K. Pathak, M. B. Johnston, A. Petrozza, L. M. Herz and H. J. Snaith, Energy Environ. Sci., 2014, 7, 3061-3068.

18. E. R. Dohner, E. T. Hoke and H. I. Karunadasa, J. Am. Chem. Soc., 2014, 136, 1718-1721.

19. T. Ishihara, J. Takahashi and T. Goto, Phys. Rev. B, 1990, 42, 11099.

20. Z. Yuan, C. Zhou, Y. Tian, Y. Shu, J. Messier, J. C. Wang, L. J. Van De Burgt, K. Kountouriotis, Y. Xin and E. Holt, Nat. Commun., 2017, 8, 14051.

21. C. Zhou, Y. Tian, Z. Yuan, H. Lin, B. Chen, R. Clark, T. Dilbeck, Y. Zhou, J. Hurley and J. Neu, ACS Appl. Mater. Interfaces, 2017, 9, 44579-44583.

22. Z. Zhuang, C. Peng, G. Zhang, H. Yang, J. Yin and H. Fei, Angew. Chem. Int. Ed., 2017, 56, 14411-14416.

23. A. Yangui, S. Pillet, E.-E. Bendeif, A. Lusson, S. Triki, Y. Abid and K. Boukheddaden, ACS Photonics, 2018, 5, 1599-1611.

24. M. Aamir, M. Sher, M. D. Khan, M. A. Malik, J. Akhtar and N. Revaprasadu, Mater. Lett., 2017, 190, 244-247.

25. J. Akhtar, M. Afzaal, M. A. Vincent, N. A. Burton, I. H. Hillier and P. O'Brien, Chem. Commun., 2011, 47, 19911993. 


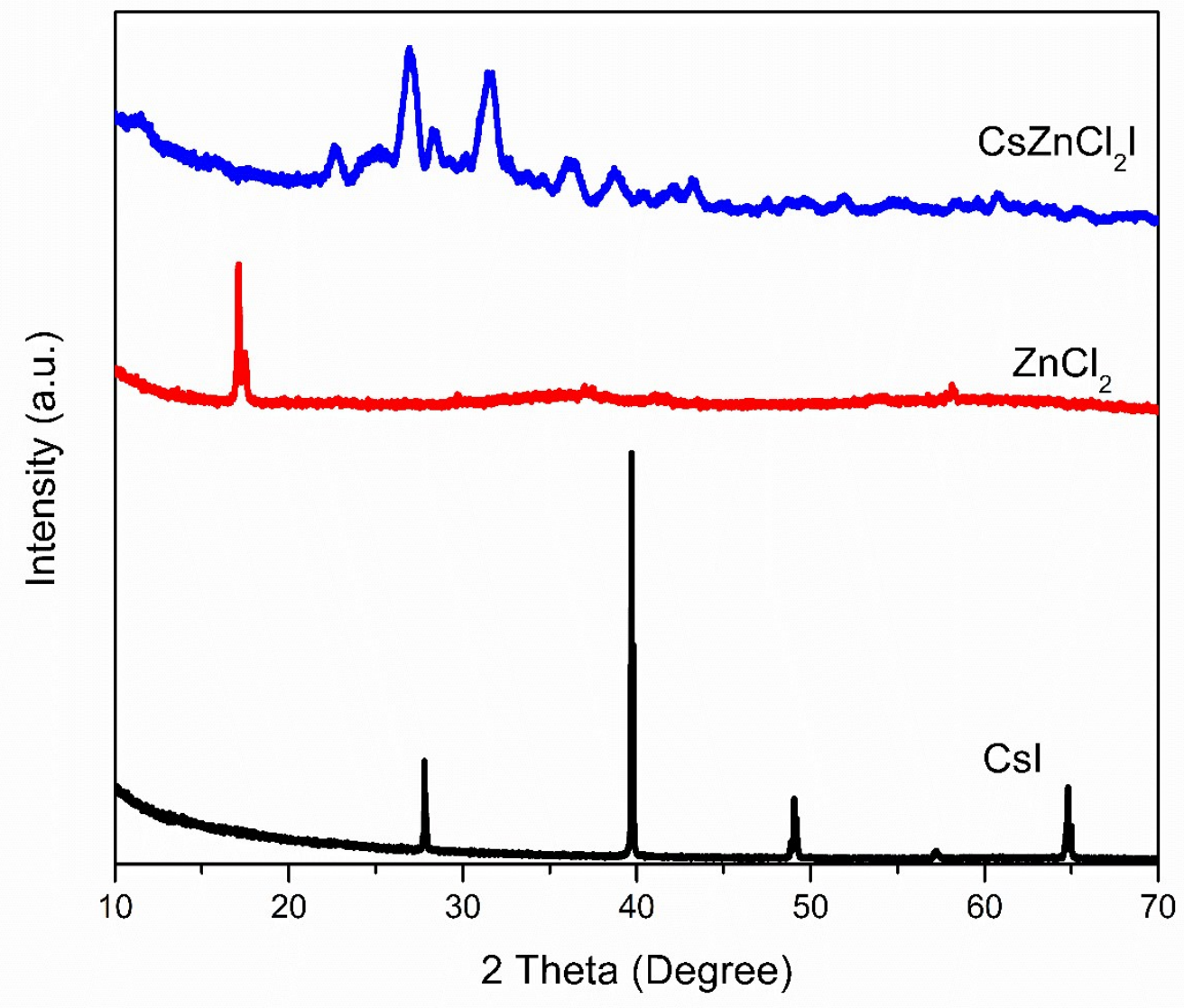

Figure 1. Comparative pXRD spectra of as-deposited $\mathrm{CsZnCl}_{2} 1$ perovskite thin film, $\mathrm{Csl}$ and $\mathrm{ZnCl}_{2}$. 

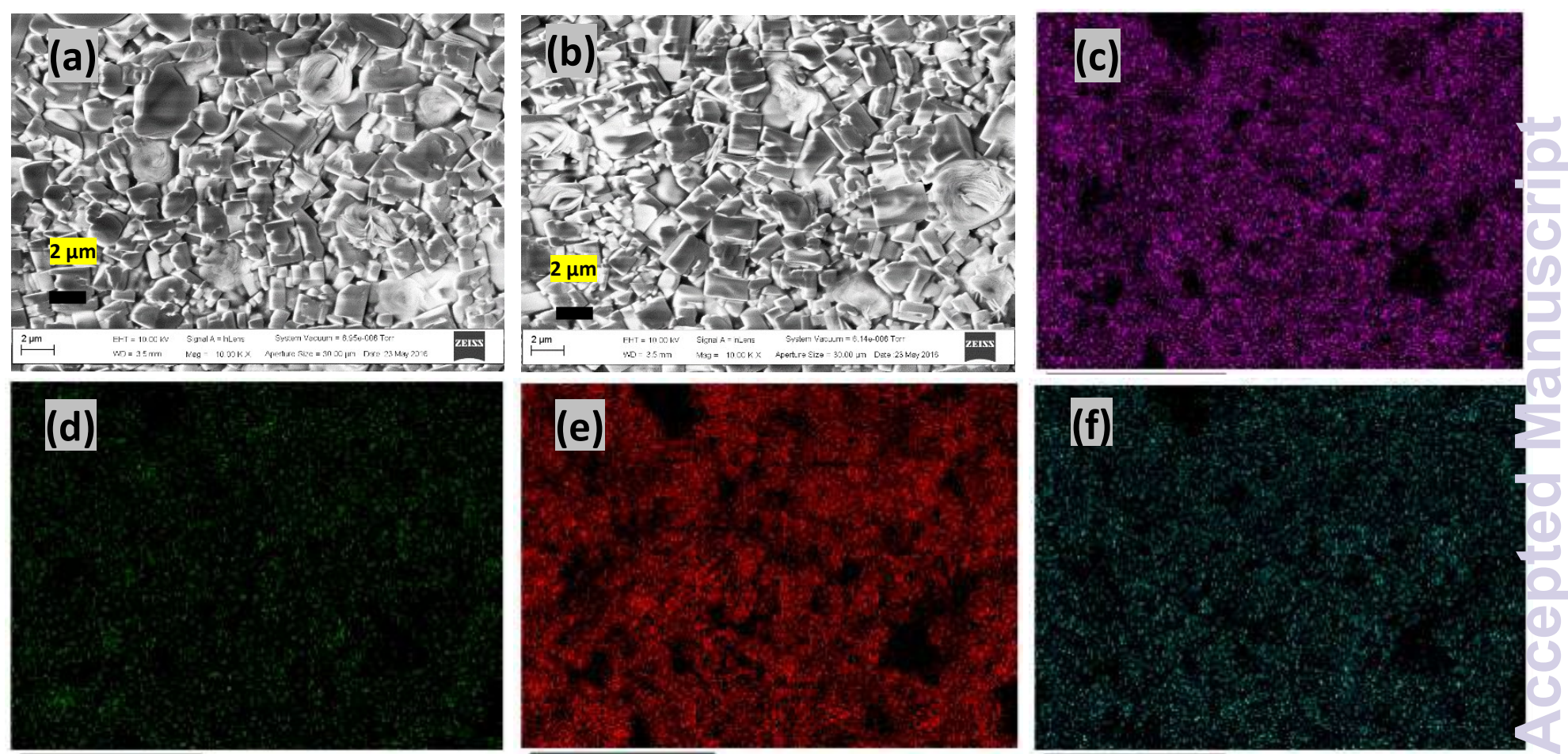

Figure 2. (a-b) SEM images of $\mathrm{CsZnCl}_{2}$ I thin films deposited by AACVD, whereas, EDX elemental analysis confirms the presence of (c) Cs, (d) $\mathrm{Zn}$, (e) Cl and (f) I in the interrogated area of deposited film. 


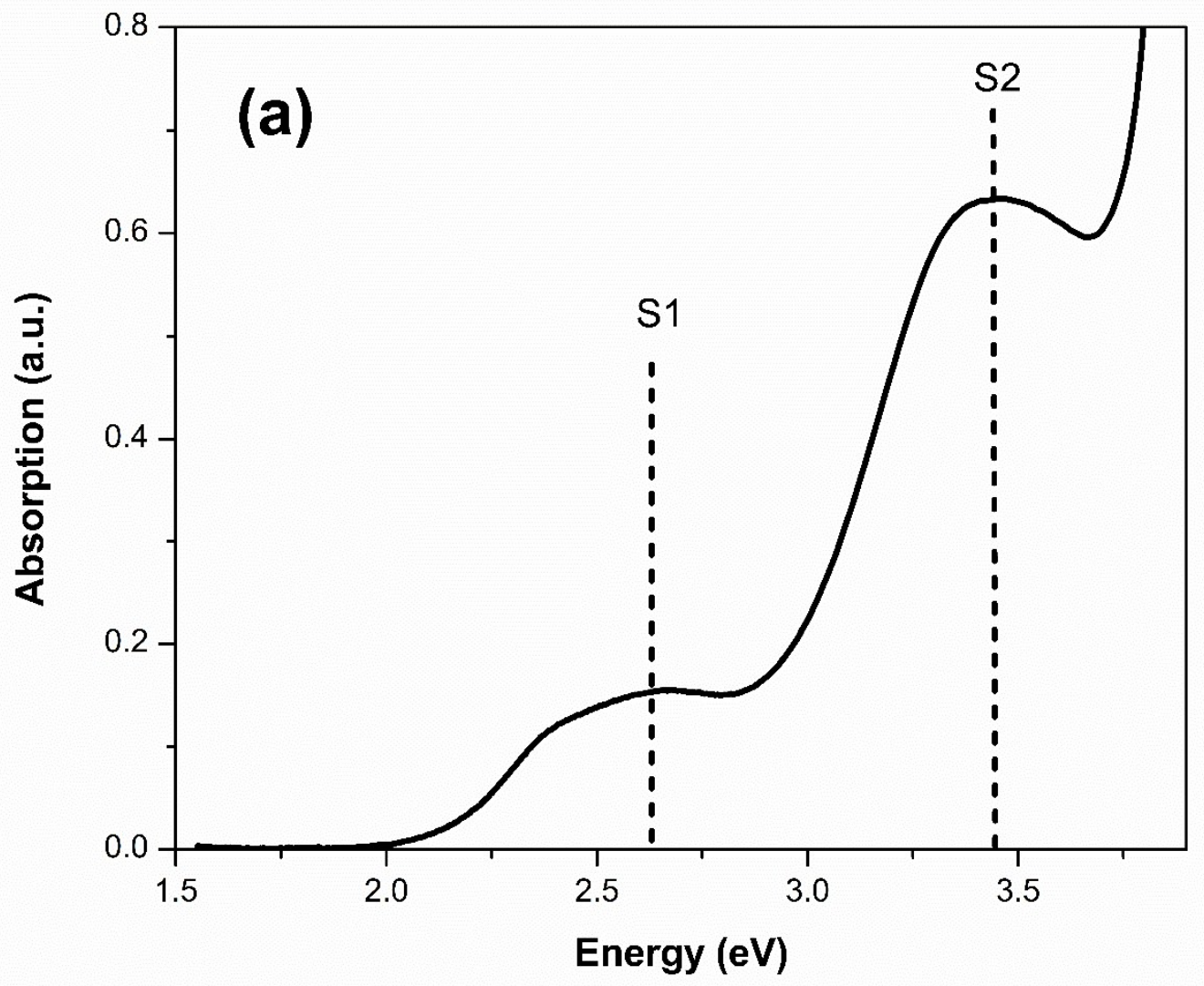




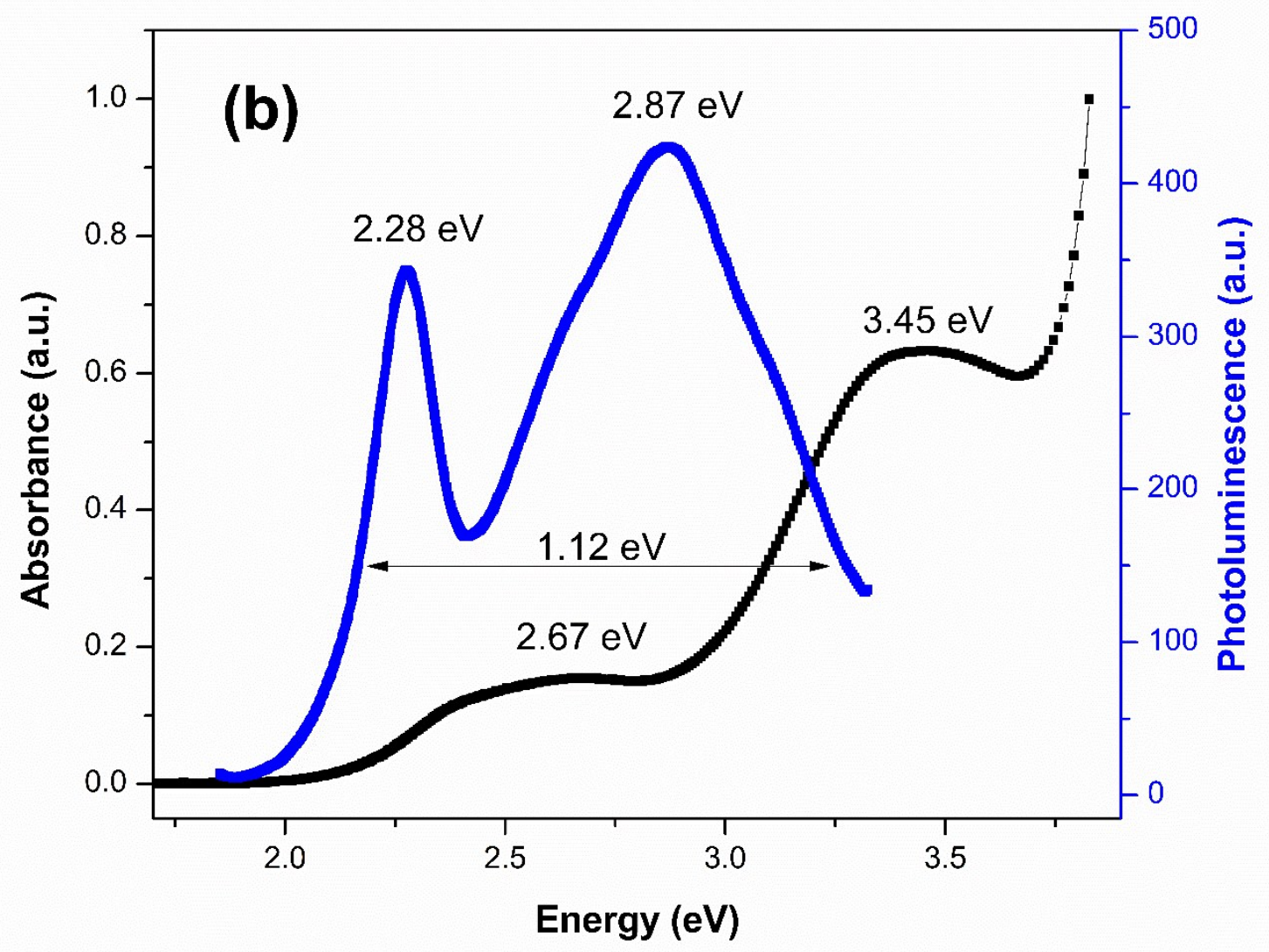

Figure 3. (a) UV-Vis absorption spectra and (b) comparative PL and UV-Vis spectra of as-deposited thin films of $\mathrm{CsZnCl}_{2} 1$. 


\section{TOC}

The Broadband emission was observed in new lead free all-inorganic $3 \mathrm{D} \mathrm{CsZnCl}_{2} \mid$ perovskite thin films deposited by AACVD.

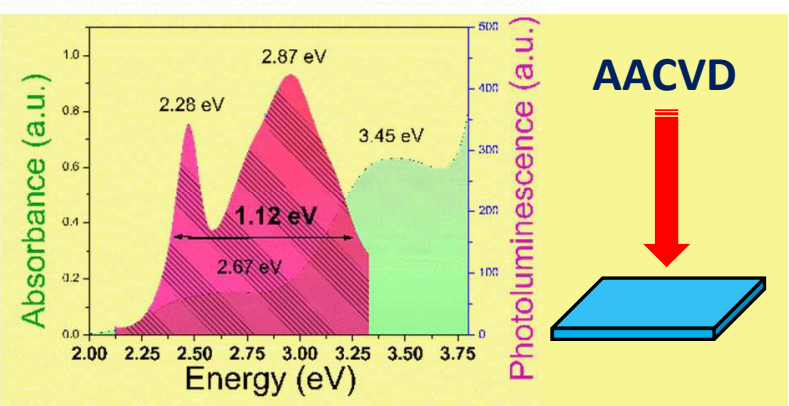

